\title{
Characterization and taste masking evaluation of microparticles with cetirizine dihydrochloride and methacrylate-based copolymer obtained by spray drying
}

\author{
ALEKSANDRA AMELIAN ${ }^{1,2}$ \\ MARTA SZEKALSKA ${ }^{1}$ \\ PATRYCJA CIOSEK ${ }^{3}$ \\ ANNA BASA ${ }^{4}$ \\ KATARZYNA WINNICKA ${ }^{1 *}$ \\ ${ }^{1}$ Department of Pharmaceutical \\ Technology, Medical University \\ of Białystok, Biatystok 15-222, Poland \\ ${ }^{2}$ Department of Clinical Pharmacy \\ Medical University of Białystok \\ Biatystok 15-222, Poland \\ ${ }^{3}$ Department of Microbioanalytics \\ Warsaw University of Technology \\ Warszaw 00-664, Poland \\ ${ }^{4}$ Department of Physicochemical \\ Analysis, University of Biatystok \\ Białystok 15-399, Poland
}

Accepted August 20, 2016

Published online August 26, 2016

\begin{abstract}
Taste of a pharmaceutical formulation is an important parameter for the effectiveness of pharmacotherapy. Cetirizine dihydrochloride (CET) is a second-generation antihistamine that is commonly administered in allergy treatment. CET is characterized by extremely bitter taste and it is a great challenge to successfully mask its taste; therefore the goal of this work was to formulate and characterize the microparticles obtained by the spray drying method with CET and poly(butyl methacrylate-co-(2-dimethylaminoethyl) methacrylate-co-methyl methacrylate 1:2:1 copolymer (Eudragit E PO) as a barrier coating. Assessment of taste masking by the electronic tongue has revealed that designed formulations created an effective taste masking barrier. Taste masking effect was also confirmed by the in vivo model and the in vitro release profile of CET. Obtained data have shown that microparticles with a drug/polymer ratio (0.5:1) are promising CET carriers with efficient taste masking potential and might be further used in designing orodispersible dosage forms with CET.
\end{abstract}

Keywords: taste masking, electronic tongue, cetirizine dihydrochloride, microparticles, methacrylate copolymer, spray drying

Unacceptable taste is an important problem encountered in the designing of new dosage forms. Taste masking of drug substances has been continuously changing with emerging techniques and new excipients (1-7). Taste masking can be carried out by various methods, depending on the therapeutic agent and dosage form. One of the simplest taste masking methods is addition of flavors, sweeteners and effervescent agents, but it is not always effective. In recent years, methods creating a physical barrier between active ingredients and taste buds have been developed for taste masking. One of them is spray drying, a relatively simple and convenient technology for the preparation of microparticles (8-11). One of the new pharmaceutical excipients used for taste masking is Eudragit E PO. It is a

\footnotetext{
*Correspondence; e-mail: kwin@umb.edu.pl
} 
poly(butyl methacrylate-co-(2-dimethylaminoethyl) methacrylate-co-methyl methacrylate 1:2:1 copolymer with $\mathrm{pH}$ dependent solubility. It is insoluble in saliva ( $\mathrm{pH}$ 6.8-7.2) and dissolves quickly under salt formation at $\mathrm{pH}$ values below 5 , which ensures effective protection in the mouth and fast drug release in the stomach. Another major benefit of this polymer is its combining taste masking with moisture protection (7).

Cetirizine dihydrochloride (CET) is a commonly used antihistaminic drug in the treatment of allergies, hay fever or urticaria (12). CET is applied as a model drug because its extremely bitter taste hinders formulation of orodispersible dosage forms, in which efficient taste masking effect is necessary. Various methods for masking CET bitter taste have been reported, such as: complexation with cyclodextrins and ion exchange resins (13-15), hot-melt extrusion (16) or fluidized bed coating (17). Another approach to mask the bitter taste of drugs is the use of taste masking polymers; therefore the goal of this work was to formulate and characterize the microparticles obtained by the spray drying method with CET and Eudragit E PO as coating substances. Microparticles are solid, spherical particles with the diameter size ranging from $1 \mu \mathrm{m}$ to $500 \mu \mathrm{m}$. An important stage in designing microparticles is selection of an appropriate polymeric material as the drug agent carrier, since its physicochemical properties are crucial factors in the final product performance $(9$, $10,18)$.

In order to determine whether the designed microparticles effectively mask CET taste, a human taste panel, in vitro CET release and the electronic taste sensing system (electronic tongue) were used. Electronic tongue receives information from chemicals through an electrode array, which works in a process similar to human receptors (19-21). Influence of the drug/polymer ratio and concentration of polymer solution on the characteristics of prepared microparticles was also studied.

\section{EXPERIMENTAL}

\section{Materials}

Acrylates/dimethylaminoethyl methacrylate copolymer (Eudragit E PO), stearic acid and sodium dodecyl sulfate were obtained from Evonik Industry (Germany). Talc was a product of Amara (Poland). Cetirizine dihydrochloride (CET) was a gift from ZF Polfa S.A. (Poland). Bis-(2-ethylohexal) sebacate (DOS), 2-nitrophenyl octyl ether (o-NPOE), liophilic salts: potassium tetrakis -(pentafluorophenyl)-borate (KTPC1PB), potassium tetrakis-[3,5bis-(trifluoromethyl)-phentyl]-boranate (KTFPB), tridodecylmethylammonium (TDMAC), high-molecular-weight polyvinyl chloride (PVC), ionophores: calcium (ETH 129), ammonium (ETH 6010), tridodecylamine, amine and sodium were obtained from Sigma-Aldrich Chemie Gmbh (Germany).

\section{Preparation of microparticles}

Microparticles were obtained by spray drying using a Mini Spray Dryer B-290 (Büchi Labortechnik AG, Switzerland) equipped with a standard $0.7 \mathrm{~mm}$ nozzle. In order to set optimal parameters of the spray drying process to obtain the product of desired properties, a number of preliminary tests were conducted and experimental parameters were chosen. Experiments were carried out under the following conditions: inlet temperature 
$47^{\circ} \mathrm{C}$, aspirator flow $97 \%$, feed flow $2 \mathrm{~mL} \mathrm{~min}^{-1}$, spray flow $600 \mathrm{~L} \mathrm{~h}^{-1}$. Various drug/polymer ratios (0.5:1, 1:1, 1.5:1) and different polymer concentrations (5 and $10 \%)$ were used for microparticle formulation. Talc was used as filler and sodium dodecyl sulfate as surfactant. Stearic acid was added to form a salt with Eudragit E PO. Water solution $(95: 5, V / V)$ with addition of $0.1 \mathrm{~mol} \mathrm{~L}^{-1}$ hydrochloric acid as polymer solvent was used. CET was dissolved in the polymer solution.

\section{Evaluation of microparticles}

Size and morphology analysis. - Measurements of the particle size and mean diameter were performed using an optical microscope (Motic Deutschland GmbH, Germany). Morphology of CET and the obtained microparticles was assessed under a scanning electron microscope (SEM) (S-400, Hitachi, Japan). Before SEM imaging, microparticles were sputter-coated with gold.

HPLC analysis. - The amount of CET was examined using the HPLC system Agilent Technologies 1200 and Zorbax Eclipse XDB-C18, 4.6×150 mm, $5 \mu \mathrm{m}$ column (Agilent Technologies, Germany). Data collection and analysis were conducted with Chemstation 6.0 software. Acetonitrile/water solution $(40: 60, V / V)$ with addition of $0.1 \mathrm{~mol} \mathrm{~L}^{-1}$ triethylamine ( $\mathrm{pH}$ 3.5) was used as the mobile phase. The flow rate was $1.0 \mathrm{~mL} \mathrm{~min}^{-1}$ and ultraviolet detection was done at $215 \mathrm{~nm}(22,23)$. CET retention time was $3.5 \mathrm{~min}$. Standard calibration curve was linear over the range of $1-100 \mu \mathrm{g} / \mathrm{mL}$ with the correlation coefficient $R^{2}=0.999$. The studies were carried out in triplicate.

Determination of CET loading, encapsulation efficiency and production yield. - To determine CET loading, an accurately weighed amount of microparticles (10 mg) was dissolved in 10 $\mathrm{mL} 0.1 \mathrm{~mol} \mathrm{~L}^{-1} \mathrm{HCl}$ and agitated for $1 \mathrm{~h}$, at $150 \mathrm{rpm}$, in a water bath. After filtration through $0.45 \mu \mathrm{m}$ cellulose acetate filters (Millipore, USA), CET concentration was analyzed by the HPLC method as described in point HPLC analysis. Mean drug encapsulation efficiency was computed using the equation:

$$
E E=Q_{\mathrm{a}} / Q_{\mathrm{t}} \times 100
$$

where $E E$ is percent of encapsulation efficiency, $Q_{\mathrm{a}}$ actual drug content and $Q_{\mathrm{t}}$ theoretical drug content.

The percent yield of CET in microparticles was determined using the formula:

$$
Y=m_{\mathrm{m}} / m_{\mathrm{t}} \times 100
$$

where $Y$ is percent production yield, $m_{\mathrm{m}}$ mass of microparticles and $m_{\mathrm{t}}$ theoretical mass of the drug and polymer.

Percent of CET loading in microparticles was determined using the equation:

$$
L=Q_{\mathrm{m}} / m_{\mathrm{m}} \times 100
$$

where $L$ is percent of CET loading, $Q_{\mathrm{m}}$ drug loaded in the microparticles and $m_{\mathrm{m}}$ mass of the microparticles (24). The studies were carried out in triplicate. 
Moisture content. - Moisture content in microparticles was assessed using a moisture analyzer balance (Radwag, Poland). Each formulation was analyzed in triplicate.

Taste masking evaluation by the electronic tongue. - The potentiometric electronic tongue that was applied in this study was based on 16 potentiometric standard ion-selective electrodes (ISEs): 12 cation-selective and 4 anion-selective (Fig. 1). They were equipped with polyvinyl chloride (PVC) membranes with various electroactive additives for differentiated selectivity (Table I). Preparation of the membranes and electrode conditioning was the same as for the standard (ISEs). As a reference, a standard double junction $\mathrm{Ag} / \mathrm{AgCl}$ electrode was used. This sensor array was used for static (batch) measurements of electromotive force with a potentiometric multiplexer (EMF 16 Interface, Lawson Labs Inc., USA). Before measuring microparticles, all sensors were qualified on the basis of their response repeatability and adequate sensitivity. For this study, 10 types of samples were considered: reference solution (reference electrolyte $0.0001 \mathrm{~mol} \mathrm{~L}^{-1} \mathrm{Ca}\left(\mathrm{NO}_{3}\right)_{2}, 0.0001 \mathrm{~mol} \mathrm{~L}^{-1} \mathrm{NaCl}$ ), pure CET, pure Eudragit E PO, Eudragit E PO microparticle placebo and the obtained microparticle formulations F1-F6 with Eudragit E PO and CET. Each sample was placed in $100 \mathrm{~mL}$ of deionized water; measurement time was $7 \mathrm{~min}$ with signal acquisition every $5 \mathrm{~s}$. Final output of the array was based on 10 last readings for each sensor. Samples were measured in triplicate; therefore the final data matrix to be analyzed was $300 \times 16$ (samples $x$ variables). Data were processed with the aid of Principal Component Analysis (PCA), prior to which autoscaling was applied. Each sample was analyzed in triplicate. Calculations and data analysis were conducted using MatLab (The MathWorks, Inc., USA) and Origin (Microcal Software, Inc, USA) software.

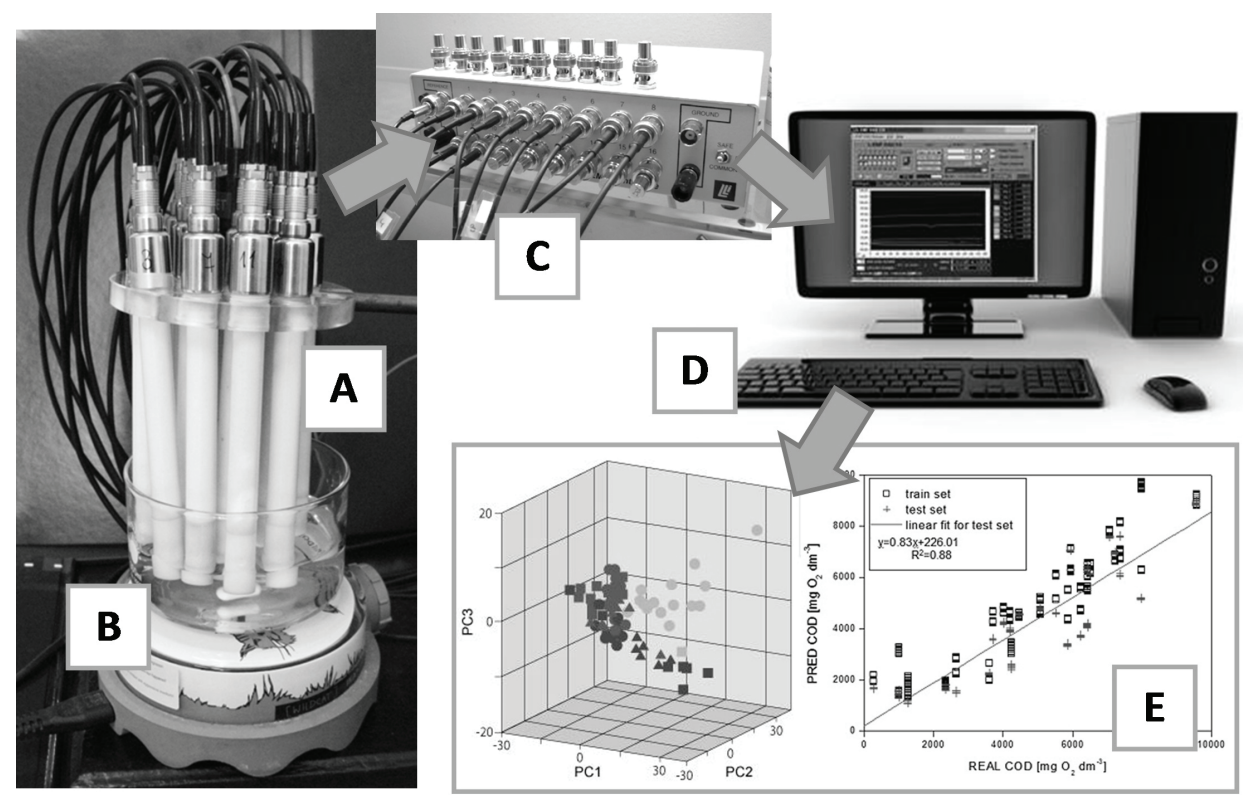

Fig. 1. Electronic tongue set-up: sensor array (A) with a sample (B), signal acquisition by a potentiometric multi-channel potentiometer (C) with L-EMF DAQ software (D), data analysis system (E). 
Table I. Components used for sensor preparation ${ }^{a}$

\begin{tabular}{|c|c|c|c|c|}
\hline Electrode type & Plasticizer & Lipophilic salt & Ionophore & $\begin{array}{l}\text { Internal filling/conditioning } \\
\text { solution (conc. in } \mathrm{mol} \mathrm{L}^{-1} \text { ) }\end{array}$ \\
\hline $\begin{array}{l}\text { CA-1 } \\
\text { CA-2 }\end{array}$ & DOS & КТРСІРВ & ETH 129 & $\mathrm{CaCl}_{2}(0.01 / 0.001)$ \\
\hline $\begin{array}{l}\text { AM-1 } \\
\text { AM-2 }\end{array}$ & DOS & - & Amine ionophore I & $\mathrm{KCl}(0.01 / 0.001)$ \\
\hline $\begin{array}{l}\text { AMON-1 } \\
\text { AMON-2 }\end{array}$ & DOS & - & Nonactin & $\mathrm{NH}_{4} \mathrm{Cl}(0.01 / 0.001)$ \\
\hline $\begin{array}{l}\text { NA-1 } \\
\text { NA-2 }\end{array}$ & DOS & КТРСІРВ & Sodium ionophore $X$ & $\mathrm{NaCl}(0.01 / 0.001)$ \\
\hline $\begin{array}{l}\mathrm{H}-1 \\
\mathrm{H}-2\end{array}$ & DOS & KTFPB & Tridodecylamine & $\begin{array}{c}\mathrm{KH}_{2} \mathrm{PO}_{4}(0.25) \\
\mathrm{Na}_{2} \mathrm{HPO}_{4}(0.25) \\
\mathrm{NaCl}(0.1) / \\
\mathrm{KH}_{2} \mathrm{PO}_{4}(0.025) \\
\mathrm{Na}_{2} \mathrm{HPO}_{4}(0.025) \\
\mathrm{NaCl}(0.01)\end{array}$ \\
\hline $\begin{array}{l}\text { CARB-1 } \\
\text { CARB-2 }\end{array}$ & DOS & TDMAC & ETH 6010 & $\begin{array}{c}\mathrm{NaH}_{2} \mathrm{PO}_{4}(0.1) \\
\mathrm{Na}_{2} \mathrm{HPO}_{4}(0.1) \\
\mathrm{NaCl}(0.01) / \\
\mathrm{NaH}_{2} \mathrm{PO}_{4}(0.01) \\
\mathrm{Na}_{2} \mathrm{HPO}_{4}(0.01) \\
\mathrm{NaCl}(0.001)\end{array}$ \\
\hline $\begin{array}{l}\mathrm{CS}-1 \\
\mathrm{CS}-2\end{array}$ & DOS & КТFРВ & - & $\mathrm{KCl}(0.01 / 0.001)$ \\
\hline $\begin{array}{l}\text { AS-1 } \\
\text { AS-2 }\end{array}$ & o-NPOE & TDMAC & - & $\mathrm{NaCl}(0.01 / 0.001)$ \\
\hline
\end{tabular}

a Description of components is given in Experimental section

In vitro drug release. - To determine CET release profiles, a USP dissolution apparatus type II (Erweka GmbH, Germany) was used. All formulations of microparticles (in an amount corresponding to $10 \mathrm{mg}$ of CET) were suspended in $750 \mathrm{~mL}$ of phosphate buffer (pH 6.8) and stirred at $75 \mathrm{rpm}$ at $37 \pm 1^{\circ} \mathrm{C}$. As CET is freely soluble in water, the sink condition was achieved during the dissolution test. At predetermined time intervals, samples were withdrawn and replaced with fresh medium. Concentration of CET was analyzed using the HPLC method as described in the point HPLC analysis. Each formulation was analyzed in triplicate.

Human taste panel. - The study was performed in a group of 6 selected healthy volunteers (Research Ethics Committee, Medical University of Białystok, approval number R-I002/262/2014). Before the test, the mouth was flushed with purified water and then a por- 
tion of microparticles corresponding to $10 \mathrm{mg}$ of CET loading was placed on the tongue for $30 \mathrm{~s}$. After this time, the oral cavity was rinsed with purified water again. To evaluate the taste, a scale with the following numerical values was used: 0 - not bitter; 1 - slightly bitter; 2 - moderately bitter and 3 - very bitter. Each formulation was analyzed in triplicate. Before the test, taste threshold evaluation was performed in 20 probands under blind conditions using a series of solutions of substances representing basic tastes: sour (tartaric acid), sweet (sucrose), salty (sodium chloride) and bitter (quinine hydrochloride). Each proband tasted some coded samples from each series with increasing concentrations of standard substances. Before the test and at the end of each quality test, assessors rinsed out their mouths with distilled water. The participants had to correctly recognize the tastant in each series. The lowest concentration correctly named was taken as the detection threshold (25). For further studies, only 6 volunteers with the highest taste recognition ability were selected.

\section{Statistical analysis}

Quantity variables were expressed as the mean and standard deviation. Statistical analysis was performed using the STATISTICA 10.0 software.

\section{RESULTS AND DISCUSSION}

\section{Characterization of microparticles obtained with CET and Eudragit E PO}

In the last few years, encapsulation of drug substances with bitter taste into polymer microparticles has been considered an efficient taste masking method. Polymer matrix creates a physical barrier, which prevents contact of the drug with the patients' gustatory bulbs. Eudragit E PO was used as a taste masking agent because it does not dissolve in the buccal cavity, thus keeping the incorporated drug intact, and ensures instant release of the active ingredient in the acidic $\mathrm{pH}$ in the stomach (7). Characteristics of microparticles formulated using the spray drying method are given in Table II.

Table II. Characteristics of microparticle formulations F1-F6 obtained with different concentrations of Eudragit ${ }^{\circledR}$ E PO solution

\begin{tabular}{lcccccc}
\hline $\begin{array}{l}\text { Formu- } \\
\text { lation }\end{array}$ & $\begin{array}{c}\text { Drug/polymer } \\
\text { ratio }\end{array}$ & $\begin{array}{c}\text { CET loading } \\
(\%)\end{array}$ & $\begin{array}{c}\text { Yield } \\
(\%)\end{array}$ & $\begin{array}{c}\text { Encapsulation } \\
\text { efficiency }(\%)\end{array}$ & $\begin{array}{c}\text { Mean size } \\
(\mu \mathrm{m})\end{array}$ & $\begin{array}{c}\text { Moisture } \\
\text { content (\%) }\end{array}$ \\
\hline F1 & $0.5: 1$ & $44.8 \pm 3.5$ & $12.0 \pm 2.1$ & $52.0 \pm 3.2$ & $4.9 \pm 2.7$ & $1.3 \pm 0.5$ \\
F2 & $1: 1$ & $52.9 \pm 2.7$ & $13.0 \pm 1.2$ & $58.9 \pm 2.2$ & $5.4 \pm 1.8$ & $1.1 \pm 0.7$ \\
F3 & $1.5: 1$ & $68.5 \pm 2.1$ & $18.5 \pm 1.2$ & $68.4 \pm 3.1$ & $6.6 \pm 2.1$ & $1.0 \pm 0.4$ \\
& & & $10 \%$ Polymer solution & & \\
F4 & $0.5: 1$ & $42.7 \pm 3.2$ & $12.3 \pm 1.2$ & $57.1 \pm 2.1$ & $4.7 \pm 3.6$ & $1.1 \pm 0.9$ \\
F5 & $1: 1$ & $60.0 \pm 2.1$ & $10.1 \pm 1.2$ & $62.8 \pm 2.0$ & $5.9 \pm 3.3$ & $1.0 \pm 0.2$ \\
F6 & $1.5: 1$ & $72.2 \pm 2.8$ & $10.0 \pm 1.0$ & $71.1 \pm 3.7$ & $8.6 \pm 2.1$ & $0.8 \pm 0.5$ \\
\hline
\end{tabular}


Comparison of particle sizes indicated that higher drug/polymer ratios resulted in larger particle sizes. Formulation F4 with the lowest CET loading (42.7\%) has the mean diameter of $4.7 \mu \mathrm{m}$, and formulation F6 with the highest CET loading (72.2\%), about 8.6 $\mu \mathrm{m}$. The drug/polymer ratio also affects the encapsulation efficiency and CET loading. In microparticles with the highest drug/polymer ratio (F3, F6), both parameters were increased. In microparticles with $5 \%$ of polymer solution, encapsulation efficiency increased from 52.0 to $68.4 \%$ and in microparticles with $10 \%$ of polymer from 57.1 to $71.1 \%$. Water content in all formulations of microparticles obtained with both polymer concentrations was similar and was in the range $0.8-1.3 \%$. Interestingly, polymer concentration (5 or 10 $\%)$ did not affect CET loading essentially, but influenced the production yield. The lowest production yield was observed with $10 \%$ polymer solution and 1.5:1 drug/polymer ratio (formulation F6). Properties of the microparticles obtained with the spray drying technique do not depend only on the drying parameters such as: inlet temperature, aspirator flow, feed flow and spray flow but also on the properties of the mixture subjected to drying. The higher the concentration of the components, the higher is the density and the lower the yield (26-28). When using methacrylate copolymers to obtain microparticles by the spray drying method, a low yield of the process is often observed. Sipos et al. noted the relationship between increased viscosity of the dried solution of ammonium methacrylate copolymer and lower yield (29). Mane et al. proposed other reasons for low efficiency of the spray drying process: the design of the cyclone separator, which is unable to trap particles below $2 \mu \mathrm{m}$ diameter, and adhesion of the particles to the inner wall of the spray dryer (30). Moreover, Kulkarni et al. suggested that low yield might be a result of electrostatic interactions between powder particles and glass walls of the drying chamber (31).

To assess surface morphology, the obtained microparticles were observed using scanning electron microscopy. All formulated microparticles were spherical in shape and had a smooth surface (data not shown). Representative SEM micrographs of pure CET and the CET microparticle formulation F4 (with the lowest CET loading) are given in Fig. 2.

\section{Taste masking evaluation of microparticles obtained with CET and Eudragit E PO}

An extremely important issue is to precisely and repeatedly assess the taste masking effectiveness; therefore in this study the taste evaluation of designed microparticles was performed by three independent methods: electronic tongue (Fig. 1), in vitro CET release and human taste panel (test in healthy volunteers).

The potentiometric electronic tongue applied in this study was based on 16 potentiometric standard ion-selective electrodes (ISEs) of various cross-selectivity according to the
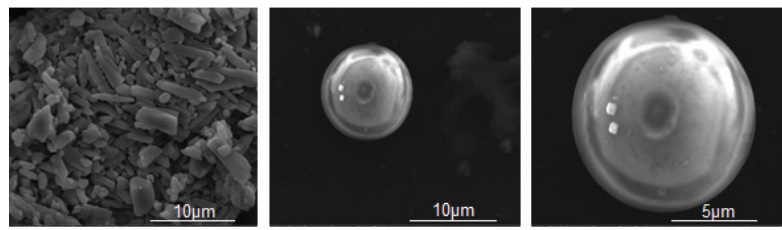

Fig. 2. SEM images: a) pure CET under magnification 10 000x, b) microparticle formulation F4 under magnification 10 000×, c) microparticle formulation F4 under magnification $20000 \mathrm{x}$. 

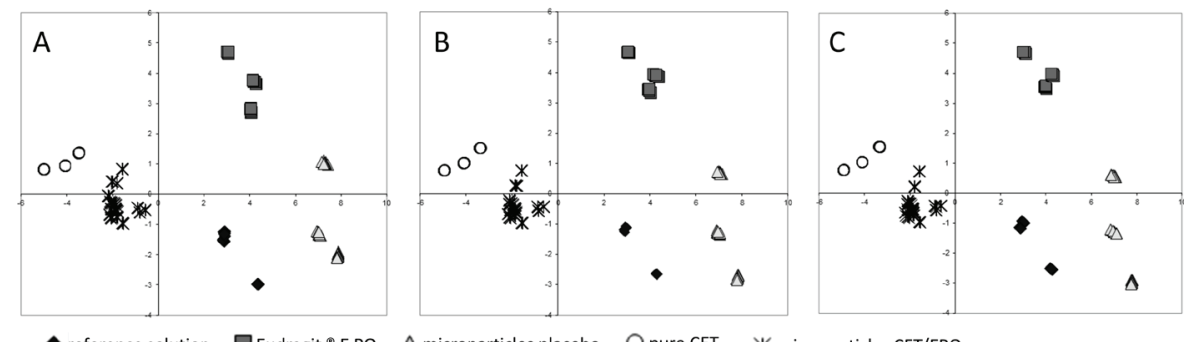

reference solution

Eudragit ${ }^{\oplus}$ E PO

$\triangle$ microparticles placebo $\bigcirc$ pure CET $\quad$ microparticles CET/EPO
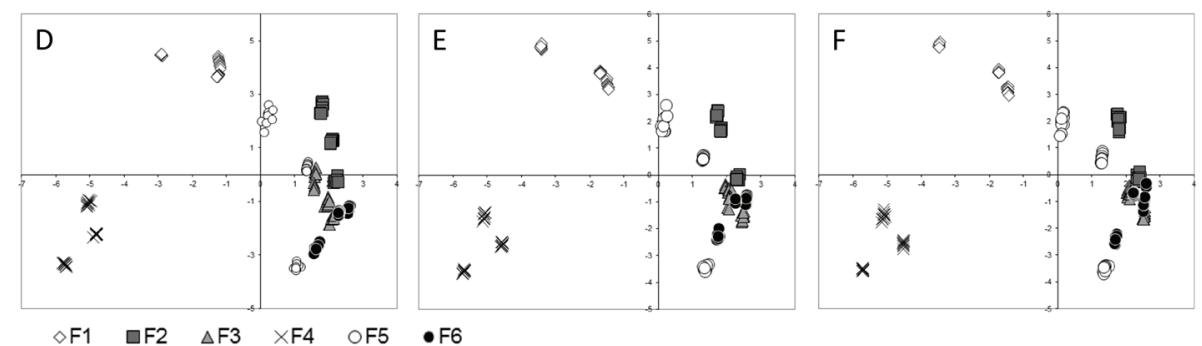

Fig. 3. Principal Component Analysis (PCA) plots showing taste clusters of the reference solution, pure CET, Eudragit E PO, microparticle placebo and microparticle formulations F1-F6 at distinct time-points of dissolution process: a) all samples after $2 \mathrm{~min}, \mathrm{~b}$ ) all samples after $5 \mathrm{~min}, \mathrm{c}$ ) all samples after $7 \mathrm{~min}$, d) microparticle formulations F1-F6 after $2 \mathrm{~min}$, e) microparticle formulations F1-F6 after $5 \mathrm{~min}, \mathrm{f}$ ) microparticle formulations F1-F6 after $7 \mathrm{~min}$.

different electroactive additives used (Table I). Such a device was utilized previously for the studies of different samples: discrimination between various formulations based on caffeine citrate (19), microencapsulated ibuprofen and roxithromycin $(20,21,32)$ and for the analysis of acetaminophen, ascorbic acid and acetylsalicylic acid in a mixture (33). Final chemical images for appropriate time points were presented on 2D-PCA plots (Figs. 3a-c). Firstly, it must be noted that distinctive clusters for all these plots are easily observable. They are formed by chemical images of samples of various types, which show appropriate classification accuracy of the electronic tongue used in this study. Secondly, formulations F1-F6 are easily discernable from both pure CET and placebo samples, showing the masking effect obtained with the use of Eudragit E PO. And finally, the structure of clusters is similar in the $2 \mathrm{nd}, 5$ th and 7 th minute of the measurement (very similar arrangement of clusters in Figs. 3d-f).

In the second part of this study, a more detailed investigation of the chemical images of 6 types of Eudragit E PO-based microparticles containing CET was performed. Data matrix $180 \times 16$ in size was processed with the aid of PCA; respective 2D-PCA plots for the 2nd, 5the and 7th minute of the measurement are given in Figs. 3d-f. Again, similar arrangement of the clusters was observable regardless of the time point. In this case, however, some formulations showed high similarity and some can be easily differentiated. The most distinct are microparticle formulations F1 and F4 (5 \% concentration of polymer, 0.5:1 


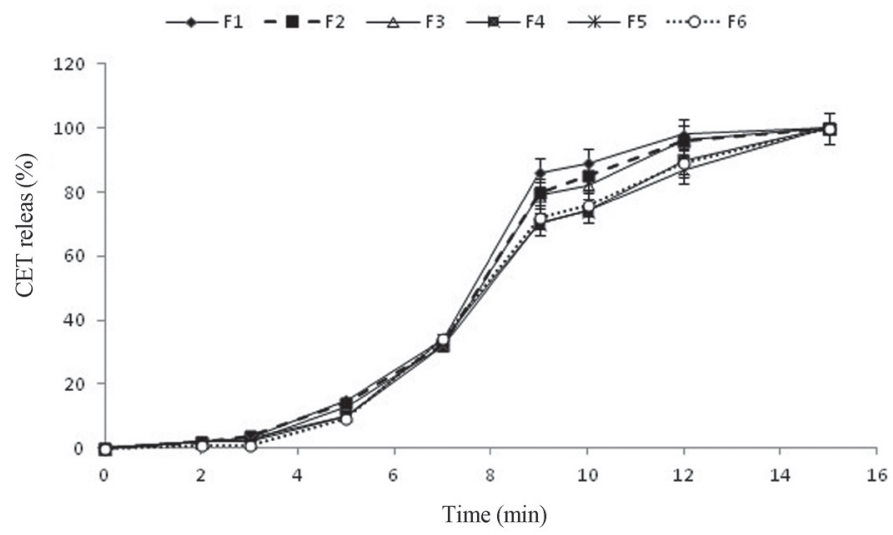

Fig. 4. In vitro CET release from microparticle formulations F1-F6 in phosphate buffer (pH 6.8).

drug/polymer ratio and $10 \%$ polymer concentration, 0.5:1 drug/polymer ratio). Higher polymer to drug ratio influenced higher similarity of the chemical images of respective formulations. In the case where the highest amount of CET was present in the microparticles (formulations F3 and F6), chemical images became almost the same - the clusters are not separable in the PC1-PC2 space. Masking effect is visible when distinct clusters are observed on the PCA score plot and this is the case in point (all formulation clusters are linearly separable from points representing pure drug; therefore the electronic tongue can see the difference between pure CET and CET microencapsulates). The first two principal components explain about $90 \%$ of variance in each case of the analysis.

Taste masking effectiveness was also evaluated by the in vitro CET release from designed microparticles. The in vitro release was carried out in phosphate buffer $\mathrm{pH} 6.8$ (corresponding to saliva $\mathrm{pH}$ ) (34). CET release profiles from microparticle formulations F1-F6 are shown in Fig. 4. In all formulations, no CET release was observed up to 3 min and 100 $\%$ of CET was released after about $15 \mathrm{~min}$.

Table III. Sensory evaluation of microparticle formulations F1-F6

\begin{tabular}{ccccccc}
\hline \multicolumn{7}{c}{ Score $^{\mathrm{a}}$} \\
\hline Volunteer & F1 & F2 & F3 & F4 & F5 & F6 \\
\hline 1 & 0 & 2 & 1 & 0 & 1 & 2 \\
2 & 1 & 1 & 1 & 0 & 1 & 1 \\
3 & 0 & 2 & 2 & 1 & 1 & 1 \\
4 & 0 & 2 & 2 & 0 & 1 & 2 \\
5 & 1 & 2 & 1 & 1 & 2 & 1 \\
6 & 0 & 1 & 1 & 0 & 1 & 2 \\
\hline
\end{tabular}

a Scored as follows: 0 - not bitter, 1 - slightly bitter, 2 - moderately bitter, 3 - very bitter. 
Taste masking efficiency of microparticles formulated with Eudragit E PO was additionally examined by 6 healthy volunteers. Organoleptic analysis of microparticles revealed that none of the tested formulations possessed intense bitter taste - no proband specified the microparticles as "very bitter", only few individuals identified the taste as moderately bitter, while the vast majority defined their taste as not bitter or slightly bitter (Table III). Moreover, the probands did not report the feeling of "spicy" or other unpleasant organoleptic sensations such as „burning tongue”. The in vivo assessment confirmed the results obtained from the electronic tongue. Formulations F1 and F4 (with the lowest CET loading) were characterized by the highest taste masking potential and created the most effective barrier. All volunteers assessed these formulations as not bitter or only slightly bitter (Table III).

\section{CONCLUSIONS}

In conclusion, three independent assessment methods for taste masking effectiveness: electronic tongue, in vitro CET release, and human taste panel revealed that Eudragit E PO with an appropriate drug/polymer ratio created an efficient taste masking barrier. Eudragit E PO can be recommended as an excipient for CET taste masking by the spray drying method and designed microparticles can be effectively used for further studies of orodispersible formulations with CET. Preparation and evaluation of orodispersible dosage forms (orally disintegrating tablets and oral lyophilisates) is in progress and will be described in due course.

Acknowledgments. - This study was conducted with the use of equipment purchased by the Medical University of Białystok as part of the OP DEP 2007-2013, Priority Axis I.3, contract No. POPW.01.03.00-20-008/09 and supported by the Medical University of Białystok grant (N/ST/ ZB/15/001/2215; 153-15554 F).

\section{REFERENCES}

1. S. Sharma and S. Lewis, Taste masking technologies: A review, Int. J. Pharm. Pharm. Sci. 2 (2010) 6-13.

2. H. Sohi, Y. Sultana and R. K. Khar, Taste masking technologies in oral pharmaceuticals: recent developments and approaches, Drug Dev. Ind. Pharm. 30 (2004) 429-448; DOI: 10.1081/DDC120037477.

3. R. Sheshala, N. Khan and Y. Darwis, Formulation and optimization of orally disintegrating tablets of sumatriptan succinate, Chem. Pharm. Bull. 59 (2011) 920-928; DOI: 10.1248/cpb.59.920.

4. R. Matsui, S. Uchida and N. Namiki, Combination effect of physical and gustatory taste masking for propiverine hydrochloride orally disintegrating tablets on palatability, Biol. Pharm. Bull. 38 (2015) 17-22; DOI: 10.1248/bpb.b14-00467.

5. Y. D. Yan, J. S. Woo, J. H. Kang, C. S. Yong and H. G. Choi, Preparation and evaluation of tastemasked donepezil hydrochloride orally disintegrating tablets, Biol. Pharm. Bull. 33 (2010) 13641370; DOI: 10.1248/bpb.33.1364.

6. D. Douroumis, Practical approaches of taste masking technologies in oral solid forms, Expert Opin. Drug Deliv. 4 (2007) 417-426; DOI: 10.1517/17425247.4.4.417. 
7. Evonik industries. Products and services: <http://eudragit.evonik.com /product/eudragit/ en/ products-services/eudragit-products/protective-formulations/e-po/Pages/default.aspx $>$, access date February 24, 2016

8. M. Szekalska, K. Winnicka, A. Czajkowska-Kośnik, K. Sosnowska and A. Amelian, Evaluation of alginate microspheres with metronidazole obtained by the spray drying technique, Acta Pol. Pharm. Drug Res. 72 (2015) 569-578.

9. D. Guajardo-Flores, C. Rempel, J. A. Gutierrez-Uribe and S. O. Serna-Saldivar, Influence of excipients and spray drying on the physical and chemical properties of nutraceutical capsules containing phytochemicals from black bean extract, Molecules 20 (2015) 21626-21635; DOI: 0.3390/ molecules201219792.

10. K. Sollohub and K. Cal, Spray drying technique: II Current applications in pharmaceutical technology, J. Pharm. Sci. 99 (2010) 587-597; DOI: 10.1002/jps.21963.

11. M. Szekalska, A. Amelian and K. Winnicka, Alginate microspheres obtained by the spray drying technique as mucoadhesive carriers of ranitidine, Acta Pharm. 65 (2015) 15-27; DOI: 10.1515/acph2015-0008.

12. Drug \& Drug Target Database. DrugBank version 4.3.: <http:// www.drugbank.ca /drugs / DB00341>, access date February 24, 2016.

13. M. Ali, M. A. El-Massik, O. Y. Abdallah and H. Abdelkader, Reduction of bitterness and enhancing palatability of cetirizine oral liquid dosage forms by cyclodextrins, JPDD 2 (2014) 102-110; DOI: 10.15744/2348-9782.1.302.

14. R. Mishra and A. Amin, Optimization and characterization of rapidly dissolving films of cetirizine hydrochloride using cyclodextrins for taste masking, Int. J. PharmTech Res. 5 (2013) 536-552.

15. M. Preis, L. Grother, P. Axe and J. Breitkreutz, In-vitro and in-vivo evaluation of taste-masked cetirizine hydrochloride formulated in oral lyophilisates, Int. J. Pharm. 491 (2015) 8-16; DOI: 10.1016/j. ijpharm.2015.06.002.

16. M. Maniruzzaman, M. Bonnefille, A. Aranyos, M. J. Snowden and D. Douroumis, An in vivo and in vitro taste masking evaluation of bitter melt-extruded drugs, J. Pharm. Pharmacol. 66 (2014) 323-337; DOI: 10.1111/jphp.12169.

17. D. D. Douroumis, A. Gryczke and S. Schminke, Development and evaluation of cetirizine HCl taste-masked oral disintegrating tablets, AAPS PharmSciTech. 12 (2011) 141-151; DOI: 10.1208/ s12249-010-9569-7.

18. D. Douroumis, Orally disintegrating dosage forms and taste-masking technologies, Expert Opin. Drug Deliv. 8 (2011) 665-675; DOI: 10.1517/17425247.2011.566553.

19. M. Pein, D. Kirsanov, P. Ciosek, M. Del Valle, I. Yaroshenko, M. Wesoły, M. Zabadaj, A. GonzalezCalabuig, W. Wróblewski and A. Legin, Independent comparison study of six different electronic tongues applied for pharmaceutical analysis, J. Pharm. Biomed. Analysis 114 (2015) 321-329; DOI: 10.1016/j.jpba.2015.05.026.

20. M. Jańczyk, A. Kutyła, K. Sołłohub, H. Wosicka, K. Cal and P. Ciosek, Electronic tongue for the detection of taste-masking microencapsulation of active pharmaceutical substances, Bioelectrochemistry 80 (2010) 94-98; DOI: 10.1016/j.bioelechem.2010.08.006.

21. K. Sołłohub, M. Jańczyk, A. Kutyła, H. Wosicka, P. Ciosek and K. Cal, Taste masking of roxithromycin by spray drying technique Acta Pol. Pharm. Drug Res. 68 (2011) 601-604.

22. B. Paw, G. Misztal, H. Hopkała and J. Drozd, Development and validation of a HPLC method for the determination of cetirizine in pharmaceutical dosage forms, Pharmazie 57 (2002) 313-315.

23. A. Jelińska, B. Stanisz, M. Zając, W. Musiał and A. Ostrowicz, Determination of cetirizine dichloride in tablets by HPLC method, Acta Pol. Pharm. Drug Res. 57 (2000) 171-173.

24. N. Yüksel, E. Dinç, F. Onur and T. Baykara, Influence of swelling degree on release of nicardipine hydrochloride from acrylic microspheres prepared by solvent evaporation method, Pharm. Dev. Technol. 3 (1998) 115-121; DOI: 10.3109/10837459809028485. 
25. M. Wesoły, M. Zabadaj, A. Amelian, K. Winnicka, W. Wróblewski and P. Ciosek, Tasting cetirizine-based microspheres with an electronic tongue, Sens. Actuators B: Chem. (2016) in press; DOI: 10.1016/j.snb.2016.06.147

26. R. P. Patel, M. P. Patel and A. M. Suthar, Spray drying technology: an overview, Indian J. Sci. Technol. 2 (2009) 44-47; DOI: 10.17485/ijst/2009/v2i10/30719

27. S. Singh and D. Dixit, A review on spray drying: emerging technology in food industry, IJAER, 4 (2014) 1-8.

28. D. E. Dobry, D. M. Settell, J. M. Baumann, R. J. Ray, L. J. Graham and R. A. Beyerinck, A modelbased methodology for spray-drying process development, J. Pharm. Innov. 4 (2009) 133-142; DOI: 10.1007/s12247-009-9064-4.

29. P. Sipos, R. Rajkó, K. Pintye-Hódi, I. Erős and P. Szabó-Révész, Formulation optimization of sustained-release ammonio methacrylate copolymer microspheres. Effects of Log P and concentration of polar cosolvents, and role of the drug/copolymer ratio, Pharmaceutics 3 (2011) 830-847; DOI: 10.3390/pharmaceutics3040830.

30. R. B. Mane, C. L. Bhingare and M. R. Bhalekar, Preparation and evaluation of carvedilol microsphere by spray drying technique: Effect of process parameters on formulation, IJPQA, 4 (2013) $4-12$.

31. N. B. Kulkarni, P. S. Wakte and J. B. Naik, Metformin hydrochloride microparticles for oral controlled release: effect of formulation variables, Int. J. Pharm. Pharm Sci. 5 (2013) 135-144.

32. P. Ciosek, M. Wesoły, M. Zabadaj, J. Lisiecka, K. Sołłohub, K. Cal and W. Wróblewski, Towards flow-through/flow injection electronic tongue for the analysis of pharmaceuticals, Sens. Actuators B 207 (2015) 1087-1094; DOI: 10.1016/j.snb.2014.07.042.

33. M. Wesoły, X. Cetó, M. Del Valle, P. Ciosek and W. Wróblewski, Quantitative analysis of active pharmaceutical ingredients (APIs) using a potentiometric electronic tongue in a SIA flow system, Electroanalysis 27 (2015) 1-8; DOI: 10.1002/elan.201500407.

34. F. Ahmadi-Motamayel, M. T. Goodarzi, S. S. Hendi, H. Abddsamadi and N. Rafiean, Evaluation of salivary flow rate, $\mathrm{pH}$, buffering capacity, calcium and total protein levels in caries free and caries active adolescence, J. Dent. Oral Hyg. 5 (2013) 35-39; DOI: 10.5897/JDOH12.011. 